\title{
Fatigue analysis of thin AlMgSi welded joints under constant and variable amplitude block loadings
}

\author{
J.A.M. Pinho-da-Cruz $^{\text {a,* }}{ }^{\text {, J.A.M. Ferreira }}{ }^{\text {b }}$, J.D.M. Costa ${ }^{\text {}}$, \\ L.F.P. Borrego ${ }^{b}$ \\ ${ }^{a}$ Department of Mechanical Engineering, University of Aveiro, Campus de Santiago, 3810-193 Aveiro, \\ Portugal \\ ${ }^{\mathrm{b}}$ Department of Mechanical Engineering, University of Coimbra, Pólo II da Universidade de \\ Coimbra, 3030-201 Coimbra, Portugal
}

Received 16 April 2002; accepted 9 December 2002

\begin{abstract}
This paper reports the fatigue behaviour of thin AlMgSi1 aluminium alloy weldments and the improvement in fatigue strength due to post-weld treatments. Several fatigue tests were performed using two distinct types of thin welded joints, $\mathrm{T}$ and single lap, manufactured using a 6xxx series aluminium alloy, and the efficiency of fatigue life improvement techniques, such as post-weld heat treatment and weld toe's burr dressing, was studied. Both the post-weld heat treatment and the burr dressing produced a fatigue strength improvement. This fact is discussed, for both geometries, in the context of the initiation and propagation phases contribution to total fatigue life. Finally, several fatigue tests were performed under variable amplitude block loading using T6 post-weld heat-treated single lap joints, and the correspondent fatigue lives were compared with the predictions of Miner's rule.
\end{abstract}

(c) 2003 Elsevier Science Ltd. All rights reserved.

Keywords: Aluminium; Thin-walled sections; Welded aluminium joints; Fatigue; Life-time

* Corresponding author. Tel.: +351-234-370830; fax: +351-234-370953.

E-mail address: jpc@mec.ua.pt (J.A.M. Pinho-da-Cruz). 


\section{Introduction}

It is widely known that in the last decades aluminium alloys have been more and more used in the production industry, mainly in automotive industry. The 6xxx series alloys are commonly use in structural applications due to the fact of presenting relatively high strength, good corrosion resistance and high toughness combined with good formability and weldability. In this context, the utilisation of welded profiles leads to a reduction of structural weight and a simpler process of production. However, the geometrical discontinuities and high residual stresses associated with welded joints turn them critical points in what concerns to structural strength, especially in the presence of cyclic loading.

As in notched metal bodies, the weldments fatigue life is usually divided in two parts: an initiation (crack nucleation and short crack growth) period $N_{\mathrm{i}}$, which can occupy a substantial part of the total fatigue life of thin welded joints [1-4], and a propagation (long crack growth) period $N_{\mathrm{p}}$. There are two distinct and paradigmatic types of weldments, namely the discontinuity-containing and the discontinuity-free, exhibiting radically different fatigue behaviours. In the former weldment type, the existence of defects, such as crack-like flaws at the weld toe, readily contribute to the initiation of fatigue cracks, enhancing the preponderance of the crack propagation period. In the latter weldment type, the initiation period can represent the major part of the total fatigue life, being the crack growth relatively unimportant in discontinuity-free small-thickness weldments [5]. Several applications may allow the assumption of discontinuity-free weldments. Namely, the TIG process weld perfection may approach that of a discontinuity-free weldment [5]. Also, it has been observed that in aluminium weldments weld toe intrusions are often absent, and that crack initiation occupies a substantial part of the total life [6].

In accordance with Lawrence et al. [5], the fatigue strength of discontinuity-containing weldments cannot be improved, whereas the fatigue strength of the discontinuity-free weldments can be enhanced, generally by modification of weld toe's geometry or by the alteration of the levels of the joint residual stress field.

In constant amplitude (CA) fatigue tests, the $\mathrm{S}-\mathrm{N}$ curve is usually obtained in the following form:

$$
\Delta S^{m} N_{\mathrm{r}}=C
$$

where $\Delta S$ is the nominal stress range, $N_{\mathrm{r}}$ the number of cycles to rupture and $m$ and $C$ are the exponent and the coefficient of the $S-N$ curve, respectively.

On the other hand, the Miner's rule [7] is usually used to predict the fatigue life of specimens tested under situations of variable amplitude block (VAB) loading fatigue tests. This rule assumes a linear damage accumulation, occurring fatigue rupture when the total damage $D$ equals unity:

$$
D=\sum_{j=1}^{u} \frac{N_{j}}{N_{\mathrm{r}, j}}
$$

where $N_{j}$ is the number of applied cycles for a given stress range $\Delta S, N_{\mathrm{r}, j}$ the corre- 
spondent number of cycles to rupture, accordingly to eq. (1), and $u$ the number of distinct stress level blocks. Neglecting the existence of a fatigue limit, the substitution of eq. (1) in Miner's rule, i.e. eq. (2), enables the definition of an equivalent stress range $\Delta S_{\text {eq }}$, which is expressed by [8]:

$$
\Delta S_{\mathrm{eq}}=\left(\frac{\sum_{j=1}^{u} N_{j} \Delta S_{j}^{m}}{\sum_{j=1}^{u} N_{j}}\right)^{\frac{1}{m}}
$$

where $N_{j}$ corresponds to the applied number of cycles at a stress range $\Delta S_{j}$ and $m$ is the $S$ - $N$ curve exponent.

The main objective of the present research was to investigate the fatigue behaviour of thin AlMgSi1 aluminium alloy weldments and the improvement in fatigue strength due to post-weld treatments, namely the effect on the fatigue behaviour of weld toe's burr dressing of a T type welded joint and post-weld T6 heat treatment of a single lap type welded joint. The accuracy of Miner's rule in predicting the fatigue life of post-weld T6 heat-treated single lap joints tested under variable amplitude block loading was also evaluated.

\section{Experimental details}

In this work, an initially T6 heat-treated AlMgSi1 (6082) aluminium alloy was used. The chemical composition and the mechanical properties of this alloy are shown in Tables 1 and 2, respectively.

Two distinct series of welded specimens, $\mathrm{T}$ and single lap, were machined from sheets $3 \mathrm{~mm}$ thick, previously welded by the manual TIG process with AlMg5 (5356) alloy as filler metal. Fig. 1(a) and (b) illustrate the dimensions of the $\mathrm{T}$ and single lap specimens, respectively.

All experiments were performed in load control using a servo-hydraulic, closedloop mechanical test Instron machine with $100 \mathrm{kN}$ load capacity, interfaced to a computer for machine control and data acquisition. All tests were conducted in air, at room temperature and with a load frequency of $25 \mathrm{~Hz}$. The specimens were clamped by hydraulic grips.

Two main series of fatigue tests were performed, one with $\mathrm{T}$ specimens and

Table 1

Chemical composition (wt \%) of AlMgSil

\begin{tabular}{llllllll}
\hline $\mathrm{Si}$ & $\mathrm{Mg}$ & $\mathrm{Mn}$ & $\mathrm{Fe}$ & $\mathrm{Cr}$ & $\mathrm{Zn}$ & $\mathrm{Cu}$ & $\mathrm{Ti}$ \\
\hline 1.05 & 0.80 & 0.68 & 0.26 & 0.01 & 0.02 & 0.04 & 0.01 \\
\hline
\end{tabular}


Table 2

Mechanical properties of T6 heat-treated AlMgSil

Ultimate tensile strength, $\sigma_{\mathrm{UTS}}[\mathrm{MPa}]$ 300

Monotonic yield strength, $\sigma_{\mathrm{YS}}[\mathrm{MPa}]$

Young's modulus, $E$ [GPa]

Poisson's coefficient, $v$

Vickers hardness, $\mathrm{HV}_{50}\left[\mathrm{kgf} \mathrm{mm}^{-2}\right]$

Cyclic strain hardening exponent, $n^{\prime}$

Cyclic strength coefficient, $K^{\prime}[\mathrm{MPa}]$

Fatigue strength exponent, $b$

Fatigue strength coefficient, $\sigma_{\mathrm{f}}^{\prime}[\mathrm{MPa}]$

Fatigue ductility exponent, $c$

Fatigue ductility coefficient, $\varepsilon^{\prime}{ }_{\mathrm{f}}$

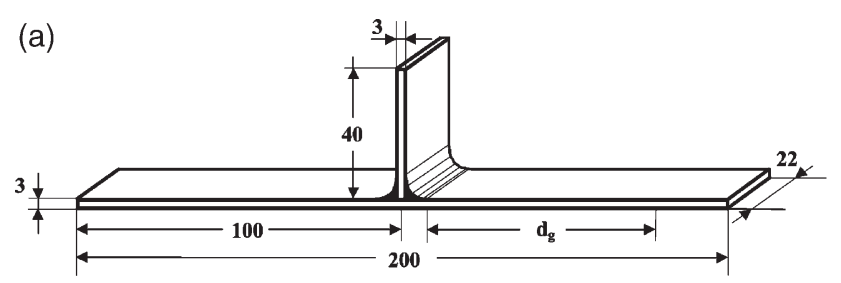

(b)

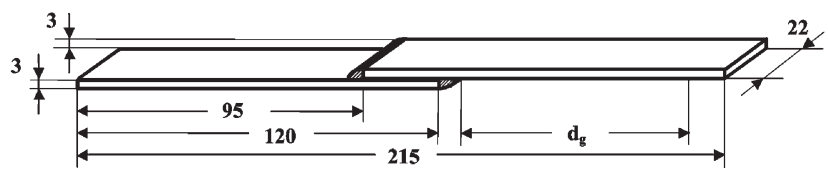

Fig. 1. Details of the welded joints (dimensions in $\mathrm{mm}$ ): (a) $\mathrm{T}$ joint, (b) lap joint.

another with single lap specimens. In both cases, the grips attachment was performed at a $50 \mathrm{~mm}$ distance $d_{\mathrm{g}}$ from the weld toe (Fig. 1(a) and (b)).

Two different types of $\mathrm{T}$ joint series, one of as-welded specimens and the other of burr-dressed specimens, were performed. Both these series were tested under constant amplitude loading with nominal stress ratio $R_{S}=0$. On the other hand, two different types of single lap joint series, one of as-welded specimens and another of post-weld T6 heat-treated specimens, were tested. The T6 heat treatment consisted, initially, in a phase of solution performed at $530{ }^{\circ} \mathrm{C}$ for $50 \mathrm{~min}$, followed by quenching in water with a cooling rate $\leq 20{ }^{\circ} \mathrm{C} / \mathrm{s}$ followed by ageing at $165{ }^{\circ} \mathrm{C}$ for $10 \mathrm{~h}$ [9]. The as-welded and a fraction of the T6 heat-treated specimens were tested under constant amplitude loading with nominal stress ratio $R_{S}=0$, while the remainder of the T6 heat-treated specimens were separated in two series, which were tested under two distinct types of variable amplitude block loading. The information related to the tested series is reported in Table 3.

Several specimens of each type of joint were randomly chosen and sliced in order to characterise the local geometry of the weldments. The slices' weld toe radii of 
Table 3

Tested specimens conditions

\begin{tabular}{llll}
\hline Series & Type & Condition & Type of loading \\
\hline 1 & $\mathrm{~T}$ & as-welded & CA $\left(R_{\mathrm{S}}=0\right)$ \\
2 & $\mathrm{~T}$ & burr-dressed & CA $\left(R_{\mathrm{S}}=0\right)$ \\
3 & single lap & as-welded & CA $\left(R_{\mathrm{S}}=0\right)$ \\
4 & single lap & T6 heat-treated & CA $\left(R_{\mathrm{S}}=0\right)$ \\
5 & single lap & T6 heat-treated & VAB $\left(P_{\min }=0 \mathrm{kN}\right)$ \\
6 & single lap & T6 heat-treated & VAB $\left(P_{\text {max }}=6 \mathrm{kN}\right)$ \\
\hline
\end{tabular}

curvature $r_{\mathrm{c}}$ were measured by mathematical manipulation of profile points obtained by the use of a Mitutoyo projector, being 2.97 and $0.7 \mathrm{~mm}$ the average radius values and 1.11 and $0.42 \mathrm{~mm}$ the standard deviation values detected, respectively, for the $\mathrm{T}$ and single lap joints. In this way, both the average and the standard deviation values of the $\mathrm{T}$ joints are greater than the single lap ones. The existence of considerable standard deviation values is due to the highly irregular three-dimensional form of the joints weld fillets, which turn the notch root radius at the failing site highly variable. In fact, microscopic examination of weld toes have shown that practically any value of radius can be observed [10].

In order to characterise the T6 heat treatment effects on the single lap joints, Vickers microhardness profiles were obtained using an indentation load of $50 \mathrm{gf}$ for $15 \mathrm{~s}$, according to the ASTM E 348 standard [11], along the longitudinal direction of as-welded and T6 heat-treated single lap joints and close to the weld toe, which is critical zone for crack initiation since it has always occurred at the weld toe. Some metallographic sample specimens were prepared, in accordance to the ASTM E 3 standard [12], and microscopic examinations of their microstructures were performed using the Keller's reagent as etchant, in accordance to the ASTM E 407 standard [13]. Finally, SEM observations of the final rupture zones were performed in single lap joints using a Siemens XL 30 scanning electron microscope.

\section{Results and discussion}

\subsection{As-welded specimens fatigue life results}

Fig. 2 presents the $\mathrm{T}$ and single lap joints as-welded specimens constant amplitude fatigue results. The remote nominal stress range $\Delta S$ is plotted against the number of cycles to rupture $N_{\mathrm{r}}$ and it can be seen that fatigue strength of T joints is greater than the one of single lap joints. In reality, the existence of a static flexural tension stress due to geometrical deformation induced by the gripping of single lap joints, which corresponds to an initial bending load [14], associated to smaller radii of curvature in this type of joints $\left(r_{c}=0.7 \pm 0.42 \mathrm{~mm}\right)$ than in $\mathrm{T}$ joints $\left(r_{c}=2.97 \pm\right.$ $1.11 \mathrm{~mm}$ ) explains the existence of higher local stress levels in single lap joints, 


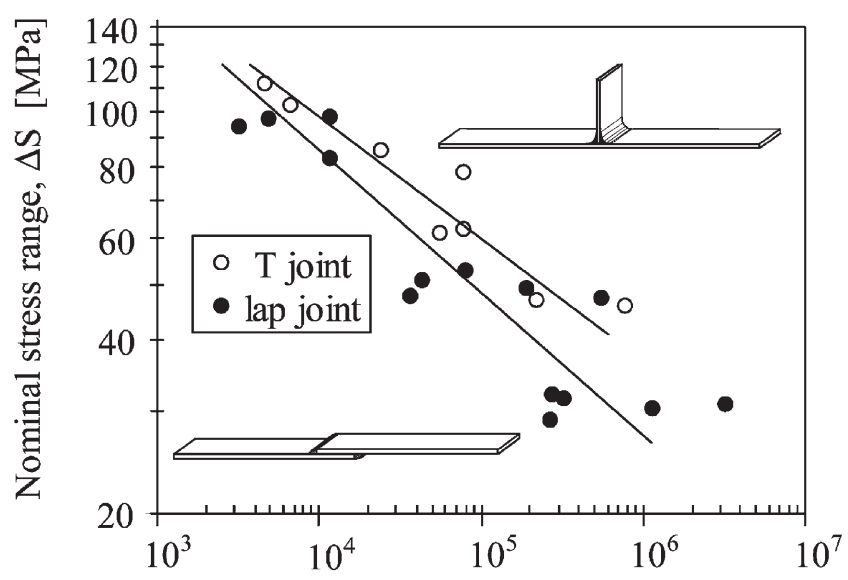

Fatigue life, $\mathrm{N}_{\mathrm{r}}$ [cycles]

Fig. 2. Experimental fatigue results of the as-welded joints.

which led consequently to a smaller fatigue strength. Table 4 presents the $S$ - $N$ curves of the as-welded specimens constant amplitude fatigue tests, obtained, in accordance to the ASTM E 739 standard [15], from regression analysis assuming $\log \left(N_{\mathrm{r}}\right)$ as the dependent variable.

\subsection{Influence of the post-weld treatments}

\subsection{1. $T$ joint}

Fig. 3 presents the results of the constant amplitude fatigue tests of the as-welded and burr-dressed $\mathrm{T}$ joints, being the nominal stress range $\Delta S$ plotted against the number of cycles to rupture $N_{\mathrm{r}}$. Burr-dressed T specimens present an improvement of fatigue life in relation to as-welded ones. An improvement of about $18 \%$ of the stress range for a fatigue life of $10^{5}$ cycles can be explained by the fact of the burr dressing operation not only have promoted the removal of weld toe's surface defects, leading consequently to a greater initiation period, but also originated greater weld toe's radii of curvature and, consequently, lower local stress levels. The slope of a

Table 4

Regression equations for CA S-N data

\begin{tabular}{lll}
\hline Series & Type & Regression equation \\
\hline 1 & $\mathrm{~T}$ & $\Delta S^{4.8} \mathrm{Nr}=4 \times 10^{13}$ \\
2 & $\mathrm{~T}$ & $\Delta S^{7.0} \mathrm{Nr}=8 \times 10^{17}$ \\
3 & single lap & $\Delta S^{4.1} \mathrm{Nr}=8 \times 10^{11}$ \\
4 & single lap & $\Delta S^{6.3} \mathrm{Nr}=2 \times 10^{16}$ \\
\hline
\end{tabular}




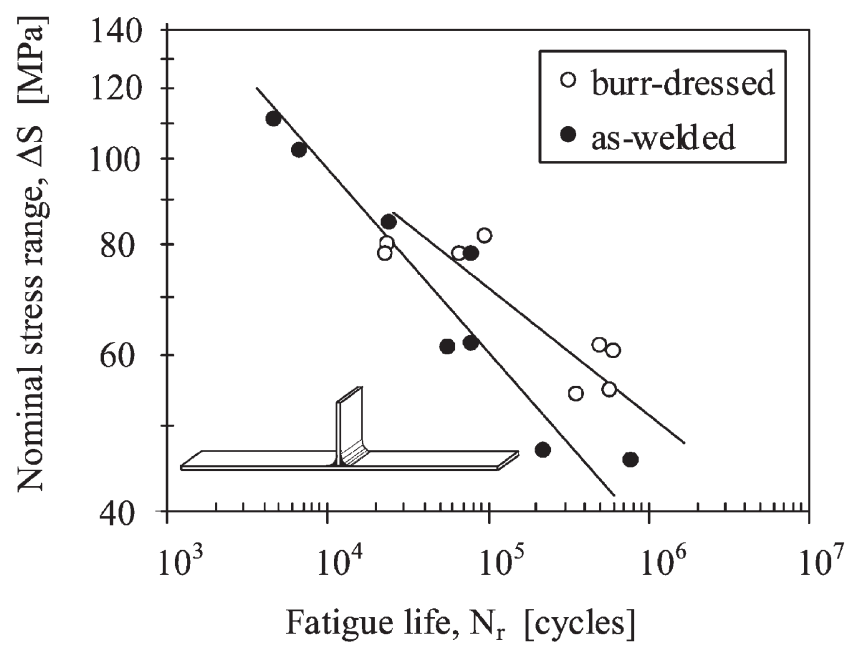

Fig. 3. Experimental fatigue results of the $\mathrm{T}$ joints.

$S-N$ curve, which numerically corresponds to $-m^{-1}$, is an incontrovertible indication of the importance of the fatigue initiation period [5]. The fact of a $S-N$ curve present a more horizontal slope indicates a greater contribution of the initiation period to the total fatigue life, as illustrated in Fig. 4. Thus, a higher fatigue crack initiation period due to burr dressing is reflected by the increase of the exponent $m$ of the T type joint $S-N$ curve which, as presented in Table 4, increased from 4.8 to 7.0.

\subsubsection{Single lap joint}

Fig. 5 presents the results of single lap joints constant amplitude fatigue tests in both as-welded and heat-treated conditions. The remote nominal stress range $\Delta S$ is plotted against the number of cycles to rupture $N_{\mathrm{r}}$. The T6 heat-treated specimens

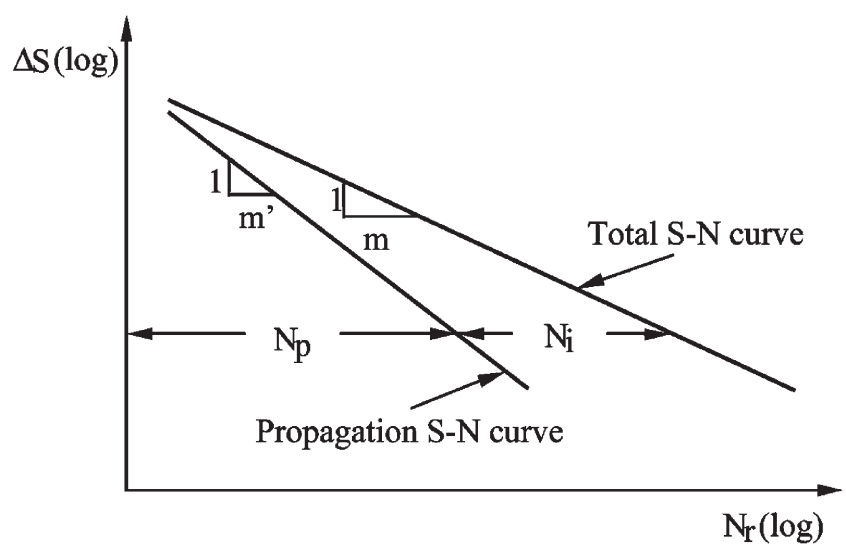

Fig. 4. Total and propagation fatigue S-N curves. 


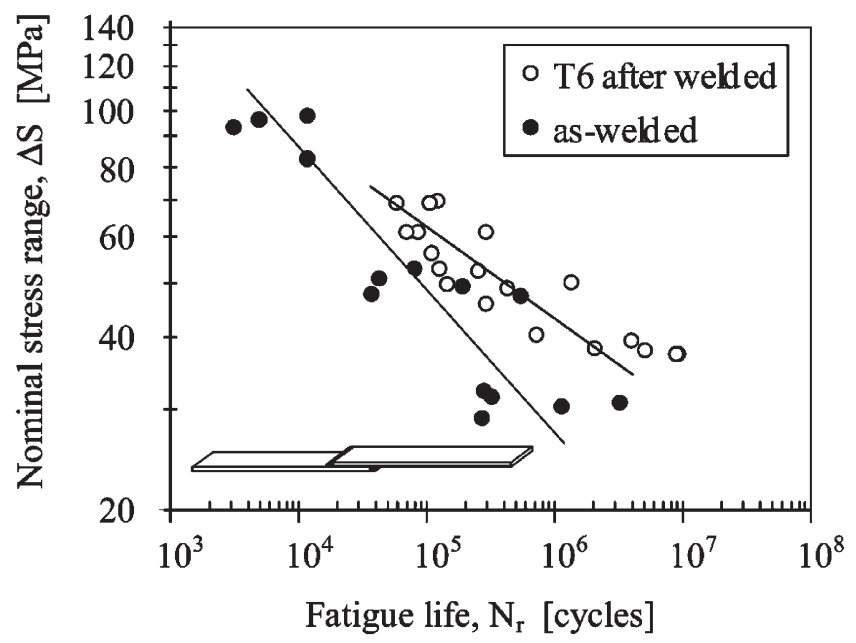

Fig. 5. Experimental fatigue results of the single lap joints.

present an improvement of about $57 \%$ of the stress range for a fatigue life of $10^{6}$ cycles in relation to as-welded ones. As for the case of the $\mathrm{T}$ joints, a higher fatigue crack initiation period due to T6 heat-treatment is reflected by the increase of the exponent $m$ of the correspondent $S-N$ curve which, as presented in Table 4, increased from 4.1 to 6.3. It is worth to note that, in accordance with Borrego et al. [16], the Paris' law exponent $m^{\prime}$ of the AlMgSi1-T6 alloy equals 3.544 for a nominal stress ratio $R_{S}=0.05$, being this coefficient related to the contribution of the propagation period to the total fatigue life, as presented in Fig. 4.

The existence of tensile residual stresses in a surface layer accelerates crack initiation, reducing fatigue life due to the increase of local mean stress. An improvement in the fatigue life of the welded joints can be related to the fact that generally the $\mathrm{T} 6$ heat treatment produces an almost completely relief of tensile residual stresses in Al-alloy weldments [17].

A recovery of the tensile strength of the welded specimens, namely $\sigma_{Y S}=106$ $\mathrm{MPa}$ and $\sigma_{\text {UTS }}=140 \mathrm{MPa}$, to the original strength of the parent metal, namely $\sigma_{Y S}=245 \mathrm{MPa}$ and $\sigma_{U T S}=300 \mathrm{MPa}$, was observed. Fig. 6(a) and (b) illustrate that the rupture zone of the heat-treated joint presents dimples of minor dimension than the one of the as-welded joint, a fact that can be associated to the mechanical resistance increase.

The Vickers microhardness profiles of as-welded and T6 heat-treated single lap joints along the longitudinal direction and close to the weld toe are presented in Fig. 7. From the as-welded joint hardness profile it can be concluded that the thermal effects of the welding process induce a material softening, mainly in the vicinity of the weld toe. A $7 \mathrm{~mm}$ HAZ extension was found with a minimum hardness of 54 $\mathrm{HV}_{50}$ at about $0.5 \mathrm{~mm}$ from the weld toe. On the other hand, the T6 heat-treated joint hardness profile suggests that $\mathrm{T} 6$ heat treatment recovered hardness to the original value of the parent metal $\left(100 \mathrm{HV}_{50}\right)$. 

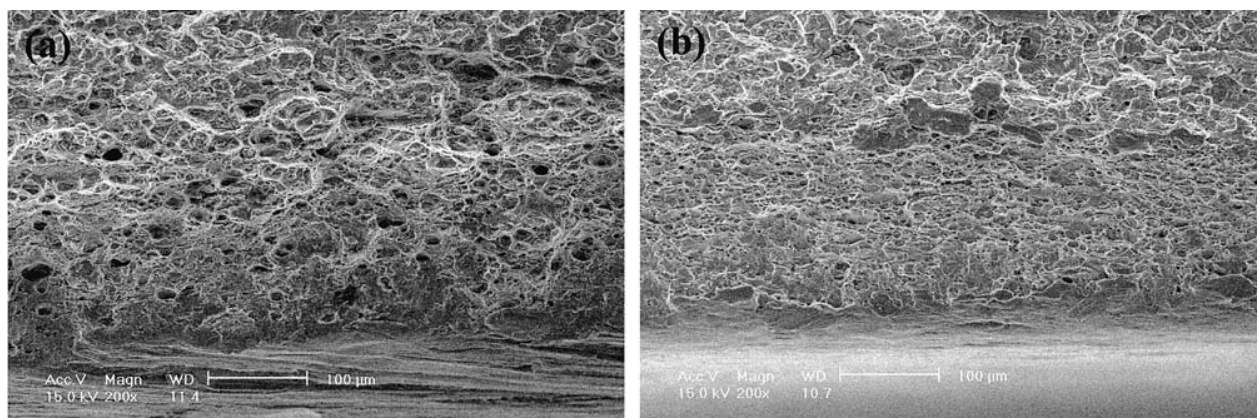

Fig. 6. SEM micrograph of the rupture zone: (a) as-welded joint, (b) T6 heat-treated joint.

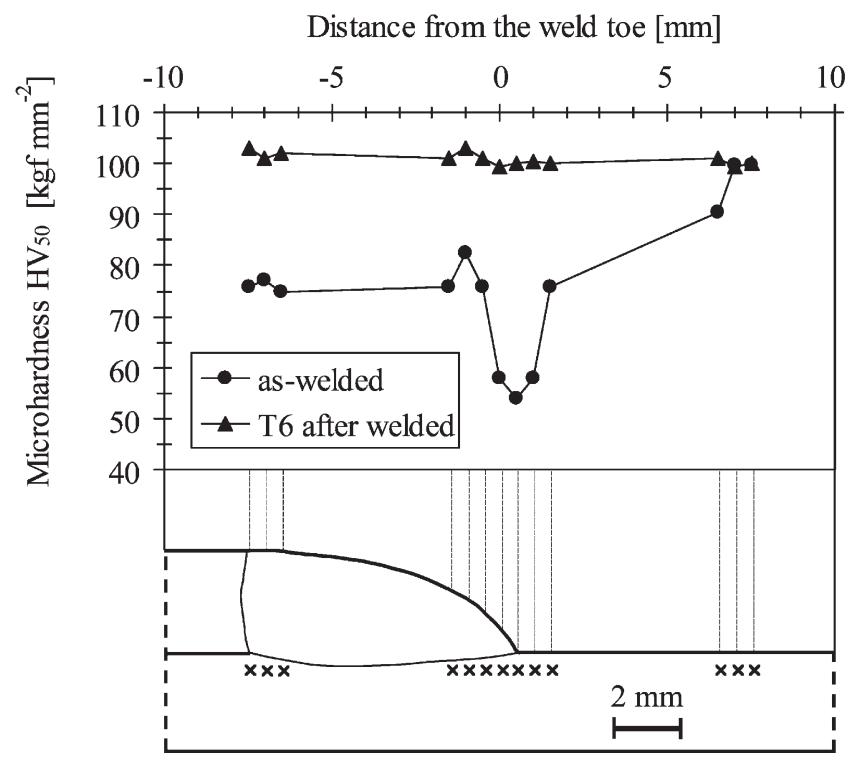

Fig. 7. Microhardness profiles of single lap joints.

The recovery of both monotonic mechanical properties and hardness of the welded material results from the T6 precipitation-strengthening process. Fig. 8(a) illustrates a micrograph of the as-welded joint fusion zone, where a net of interdendritic $\mathrm{Mg}_{2} \mathrm{Si}$ eutetic, originated by the thermal welding effects, can be observed. As referred before, the solution treatment, followed by quenching and final ageing, leads to the eutetic net disappearance and gives origin to a dense and fine dispersion of intermetallic $\mathrm{Mg}_{2} \mathrm{Si}$ compound, as presented in Fig. 8(b), which strengthens the heattreated alloy.

In this way, the increase in fatigue strength of T6 heat-treated single lap joints can be explained by two main mechanisms: firstly by the relief of welding process tensile residual stresses, which lead to a greater crack initiation period and conse- 

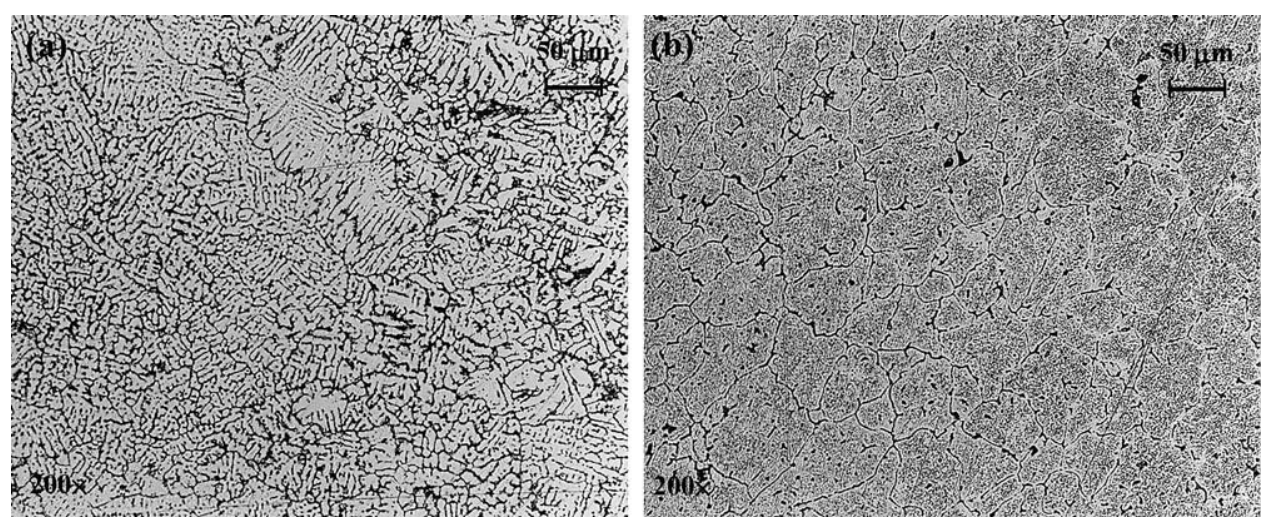

Fig. 8. Micrograph of the fusion zone: (a) as-welded joint, (b) T6 heat-treated joint.

quently to a longer fatigue life by the reduction of local mean stresses, and secondly by the increase in fatigue strength of the HAZ, due to the recovery of both monotonic mechanical properties and hardness of the welded material.

In this analysis, an improvement of fatigue strength due to both stress relief and increase of the HAZ strength properties by precipitation hardening phenomena was considered. In reality, the increase of the HAZ strength may have influence on the fatigue performance of welded joints. All the recent fatigue design rules consider fatigue live of welded joints not affected by the tensile strength of the material, assuming that weldments have initial defects and thereby the major part of the fatigue life spent in crack propagation, which is insensitive to material mechanical strength [18-21]. Although mechanical strength may be modified by heat treatments, the crack propagation rates are relatively insensitive to such changes [19,22]. In fact, the variation of HAZ microstructure and hardness levels in the weldment area has little or no effect in the crack propagation rate [20]. However, there are some weldments where the initiation life may occupy a substantial part or almost all of the total fatigue life. In that case, since the initiation life is affected by the material microstructure and hardness [23], the fatigue performance is property-dependent. In fact, a softer, large grained and more extensive weldment HAZ leads to an easier crack initiation [23,24]. Thus, the modification of the microstructure induced by the T6 heat treatment tends to increase the material mechanical strength, leading to an increase of fatigue resistance relatively to just stress relieved material [17].

Finally, it is worthwhile to note that, although the hardness and microstructure effect on weldments fatigue life is not relevant if one designs welded joints using the provision of BS 8118 [25], this effect in fatigue strength really exists [24].

\subsection{Fatigue life results for variable amplitude block loading}

Two series of variable amplitude block fatigue tests were performed. In one of them maximum load remained constant at $6 \mathrm{kN}$ (Fig. 9(a)), while in the other minimum load remained null (Fig. 9(b)). Tables 5 and 6 summarise the variable amplitude 
(a)

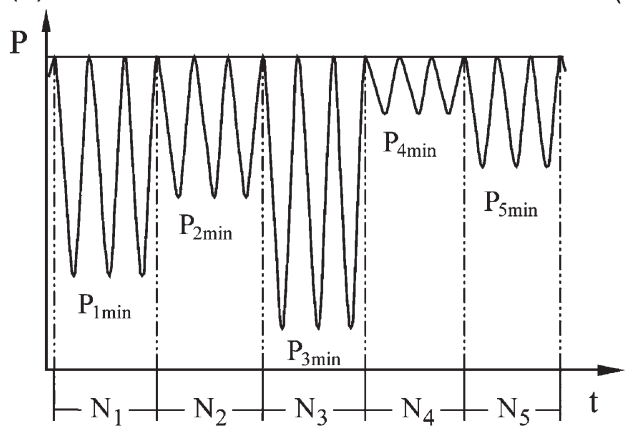

(b)

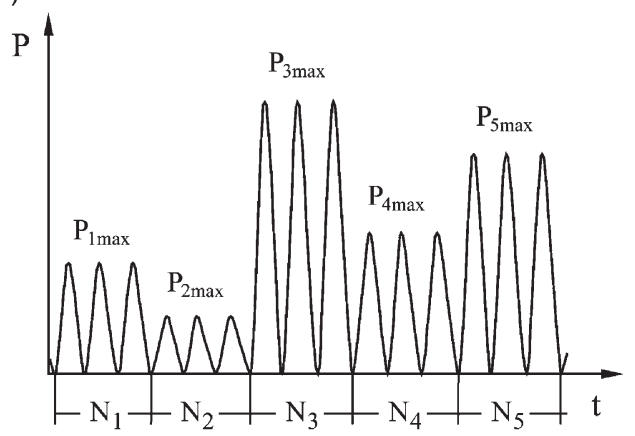

Fig. 9. Type of variable amplitude block tests: (a) $\mathrm{P}_{\max }=6 \mathrm{kN}$, (b) $\mathrm{P}_{\min }=0$.

Table 5

Variable amplitude block test conditions and results. $P_{\max }=6 \mathrm{kN}$

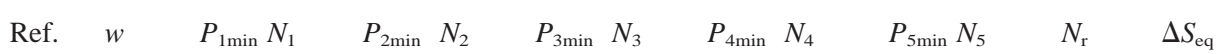
$[\mathrm{mm}][\mathrm{kN}][$ cycles] $[\mathrm{kN}]$ [cycles] $[\mathrm{kN}]$ [cycles] [kN] [cycles] [kN] [cycles] [cycles] [MPa]

\begin{tabular}{rrrrrrrrrrrrrr}
\hline VAB1 & 21.1 & 3.0 & 1200 & 2.7 & 2400 & 3.3 & 1800 & 3.5 & 600 & 2.9 & 3000 & 522000 & 48.6 \\
VAB2 & 21.1 & 2.8 & 1200 & 2.5 & 2400 & 3.1 & 1800 & 3.3 & 600 & 2.7 & 3000 & 356000 & 51.7 \\
VAB3 & 21.2 & 2.6 & 1200 & 2.4 & 2400 & 2.9 & 1800 & 3.1 & 600 & 2.5 & 3000 & 345000 & 53.9 \\
VAB4 & 20.6 & 3.0 & 2400 & 2.7 & 1800 & 3.3 & 600 & 3.5 & 1200 & 2.9 & 3000 & 426000 & 49.4 \\
VAB5 & 21.1 & 3.0 & 2400 & 3.1 & 1800 & 3.3 & 1200 & 3.2 & 3000 & 3.4 & 600 & 722000 & 45.2 \\
VAB6 & 20.9 & 2.2 & 2400 & 2.4 & 3000 & 3.0 & 1200 & 2.4 & 1800 & 2.8 & 600 & 172000 & 57.0 \\
VAB7 & 21.1 & 2.8 & 600 & 3.4 & 2400 & 3.6 & 3000 & 3.0 & 1200 & 3.2 & 1800 & 902000 & 43.1 \\
\hline
\end{tabular}

Table 6

Variable amplitude block test conditions and results. $P_{\min }=0 \mathrm{kN}$

\begin{tabular}{|c|c|c|c|c|c|c|c|c|c|c|c|c|c|}
\hline Ref. & $\begin{array}{l}w \\
{[\mathrm{~mm}]}\end{array}$ & $\begin{array}{l}P_{1 \max } \\
{[\mathrm{kN}]}\end{array}$ & $\begin{array}{l}N_{1} \\
\text { [cycles] }\end{array}$ & $\begin{array}{l}P_{2 \max } \\
][\mathrm{kN}]\end{array}$ & $\begin{array}{l}N_{2} \\
\text { [cycles] }\end{array}$ & $\begin{array}{c}P_{3 \max } \\
][\mathrm{kN}]\end{array}$ & $\begin{array}{l}N_{3} \\
\text { [cycles] }\end{array}$ & $\begin{array}{l}P_{4 \max } \\
][\mathrm{kN}]\end{array}$ & $\begin{array}{l}N_{4} \\
\text { [cycles] }\end{array}$ & $\begin{array}{l}P_{5 \max } \\
{[\mathrm{kN}]}\end{array}$ & $\begin{array}{l}N_{5} \\
\text { [cycles] }\end{array}$ & $\begin{array}{l}N_{\mathrm{r}} \\
\text { [cycles] }\end{array}$ & $\begin{array}{l}\Delta S_{\mathrm{eq}} \\
{[\mathrm{MPa}]}\end{array}$ \\
\hline VAB8 & 21.0 & 2.5 & 1200 & 2.9 & 1800 & 3.2 & 3000 & 3.5 & 2400 & 3.8 & 600 & 250000 & 51.5 \\
\hline VAB9 & 20.5 & 3.0 & 1200 & 3.3 & 1800 & 3.5 & 3000 & 3.7 & 2400 & 3.8 & 600 & 282000 & 57.0 \\
\hline VAB10 & 21.1 & 3.0 & 3000 & 3.3 & 2400 & 3.5 & 1800 & 3.7 & 600 & 3.8 & 1200 & 298000 & 53.7 \\
\hline VAB11 & 121.1 & 3.0 & 600 & 3.3 & 1200 & 3.5 & 1800 & 3.8 & 3000 & 4.0 & 2400 & 109000 & 59.1 \\
\hline VAB12 & 221.0 & 3.0 & 2400 & 3.2 & 600 & 3.5 & 1800 & 2.8 & 3000 & 3.6 & 1200 & 20100 & 51.0 \\
\hline VAB13 & 321.2 & 3.0 & 2400 & 3.2 & 600 & 3.4 & 1800 & 2.8 & 3000 & 3.3 & 1200 & 228000 & 49.0 \\
\hline VAB14 & 420.5 & 3.5 & 2400 & 3.1 & 600 & 2.7 & 1800 & 3.3 & 3000 & 2.9 & 1200 & 256000 & 52.6 \\
\hline
\end{tabular}

tests loadings and lives for the constant maximum load and constant minimum load blocks, respectively.

The results of the variable amplitude block fatigue tests are presented in Fig. 10, in accordance with eq. (3), together with the ones of constant amplitude heat-treated 


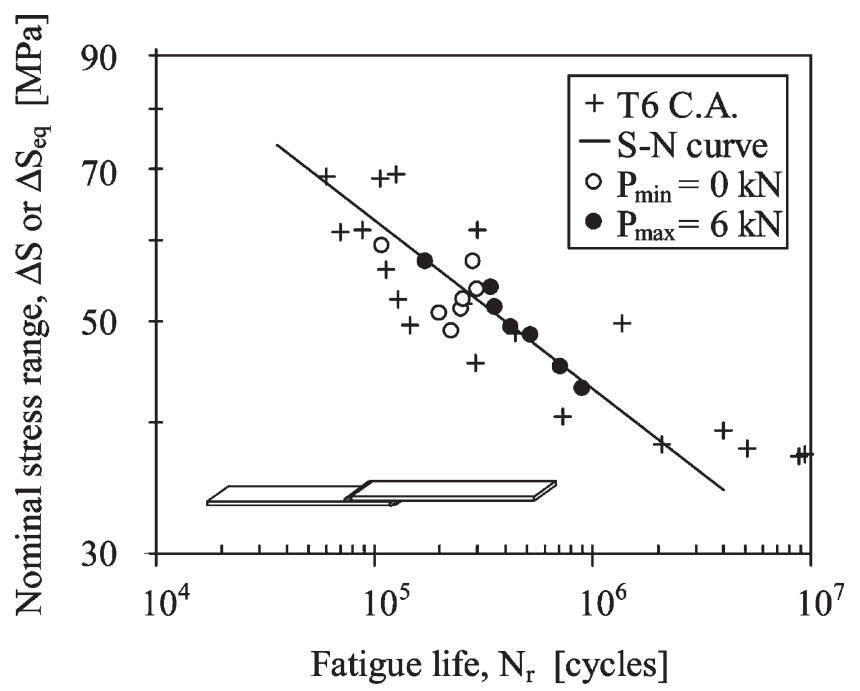

Fig. 10. Equivalent variable amplitude block fatigue results.

single lap joints. It can be verified that: (i) the results of variable amplitude block fatigue present less scattering than the constant amplitude ones, and (ii) the constant maximum load $P$ fatigue results show less scattering than the constant minimum load $P$ ones. This peculiarity can be attributed to the tendency of scatter in periodic overstrain data to be minor than in constant amplitude data [26].

Fig. 11 illustrates an equivalent representation of the variable amplitude block fatigue results, where the predicted lives $N_{\mathrm{pr}}$ were obtained by the substitution of

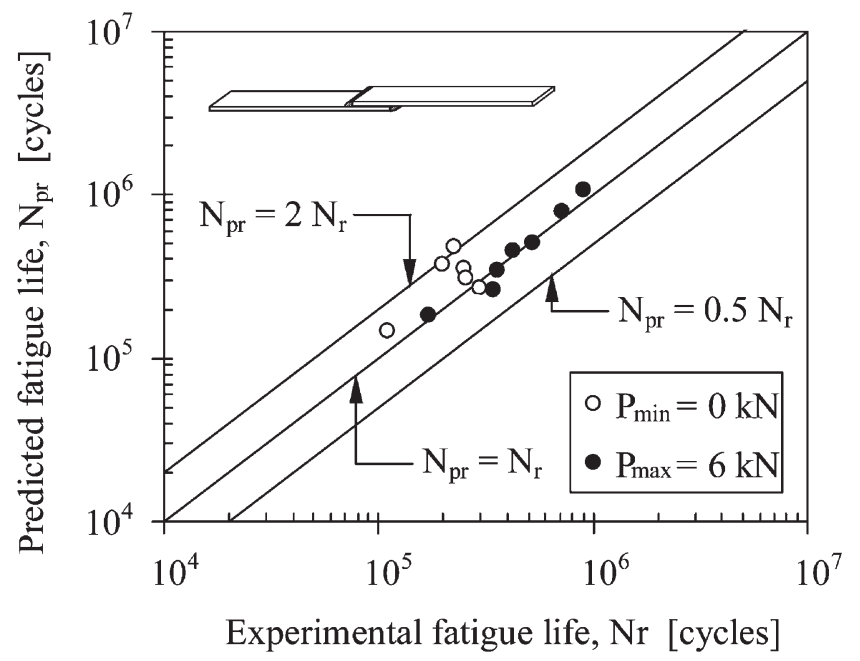

Fig. 11. Predicted versus experimental lives. 
$\Delta S_{\text {eq }}$ in eq. (1). The two plotted straight lines $N_{p r}=2 N_{r}$ and $N_{p r}=0.5 N_{r}$ were used as criterion limits of prediction exactness. The fact of the predicted lives be all almost included between these limiting lines, indicates that this method provides fairly good predictions [27] for the analysed material and loading conditions.

\section{Conclusions}

The following conclusions can be drawn from the experimental fatigue behaviour study of thin AlMgSi1 aluminium alloy weldments:

1. An improvement in fatigue behaviour was obtained in post-welded treated joints. The results have shown, firstly, that the burr dressing treatment significantly improved the fatigue strength of the $\mathrm{T}$ welded specimens, namely an improvement of about $18 \%$ of the stress range for a fatigue life of $10^{5}$ cycles, and, secondly, that the T6 heat treatment significantly improved the fatigue strength of the single lap welded specimens, namely an improvement of about $57 \%$ of the stress range was attained for a fatigue life of $10^{6}$ cycles.

2. The variable amplitude block fatigue results present less scattering than constant amplitude ones, showing constant maximum load $P$ fatigue results less scattering than the constant minimum load $P$ ones.

3. Miner's rule conducted to good life predictions for the analysed material and loading conditions.

\section{Acknowledgements}

The authors would like to acknowledge POCTI programme, project 1999/EME/32984, for funding the work reported.

\section{References}

[1] Usami S, Kimoto H, Kusomoto S. Cyclic strain and fatigue strength at the toes of heavy welded joint. Trans Japan Weld Soc 1978;9:60-90.

[2] Ho NJ, Lawrence FV. Constant amplitude and variable load history fatigue test results and predictions for cruciform and lap welds. Theor Appl Fract Mech 1984;1:3-21.

[3] Jakubczak H, Glinka G. Fatigue analysis of manufacturing defects in weldments. Int J Fatigue 1986;8:51-7.

[4] Lecsek RL, Yee R, Lambert SB, Burns DJ. A probabilistic model for initiation and propagation of surface cracks in welded joints. Fat Fract Eng Mat Struct 1995;18:821-31.

[5] Lawrence FV, Dimitrakis SD, Munse WH. Factors influencing weldment fatigue. In: Fatigue and Fracture Handbook, American Society for Metals, Fatigue and Fracture Handbook, V.19, 1996. pp.274-294.

[6] Maddox SJ. Fatigue design of welded aluminium structures. In: Proceedings of the 2nd International Conference on Aluminium Weldments, Munich, Germany, 24-26 May, 1982.

[7] Miner MA. Cumulative damage in fatigue. J Appl Mech 1945;12:A159-A64. 
[8] Ohta A, Maeda Y, Suzuki N. Fatigue strength of butt-welded joints under constant maximum stress and random minimum stress conditions. Fat Fract Eng Mat Struct 1996;19:265-75.

[9] Heat treatment of aluminium semis. Alusuisse Swiss Aluminium Ltd, 1990.

[10] Skorupa M. Fatigue crack initiation life prediction for welded joints by low cycle fatigue approach. Fat Fract Eng Mat Struct 1990;13:597-613.

[11] ASTM E 384, Standard test method for microhardness of materials. Annual Book of ASTM Standards, Vol. 03.01, USA, 1993.

[12] ASTM E 3, Standard methods of preparation of metallographic specimens. Annual Book of ASTM Standards, Vol. 03.01, USA, 1993.

[13] ASTM E 407, Standard methods for microetching metals and alloys. Annual Book of ASTM Standards, Vol. 03.01, USA, 1993.

[14] Pinho da Cruz JAM, Costa JDM, Borrego LFP, Ferreira JAM. Fatigue life prediction in AlMgSi1 lap weldments. Int J Fatigue 2000;22:601-10.

[15] ASTM E 739, Standard practice for statistical analysis of linear or linearized stress-life (S-N) and strain-life $(\epsilon-\mathrm{N})$ fatigue data. Annual Book of ASTM Standards, Vol. 03.01, USA, 1993.

[16] Borrego LP, Ferreira JM, Costa JM. Fatigue crack growth and crack closure in an AlMgSi alloy. Fat Fract Eng Mat Struct 2001;24:255-66.

[17] Bertini L, Fontanari V, Straffelini G. Influence of post weld treatments on the fatigue behaviour of Al-alloy welded joints. Int J Fatigue 1998;20:749-55.

[18] Maddox SJ. Fatigue design optimisation in welded joints. In: Proceedings of NATO Advanced Study Institute on Advances in Fatigue Science and Technology, Alvor, Portugal, 1988. NATO ASI series, series E: Applied Science, 159. Kluwer Academic Publishers, 1989, pp. 551-568.

[19] Crompton JS. Fatigue strength of aluminium alloy welds. In: Fatigue and Fracture Handbook. American Society for Metals, Fatigue and Fracture Handbook, 19;823-828, 1996.

[20] Jutla T. Fatigue and fracture control of weldments. In: Fatigue and Fracture Handbook. American Society for Metals, Fatigue and Fracture Handbook, 19;434-449, 1996.

[21] Lieurade HP. Fatigue in welded constructions-Life assessment of dynamically loaded materials and structures. In: Proceedings of 5th European Conference on Fracture, ECF 5, Lisbon, Portugal, 1984 pp.19-48.

[22] Couper MJ, Neeson AE, Griffiths JR. Casting defects and the fatigue behaviour of an aluminium casting alloy. Fat Fract Eng Mat Struct 1990;13:213-27.

[23] James MN, Paterson AE. Fatigue performance of 6261-T6 aluminium alloy-Constant and variable amplitude loading of parent plate and welded specimens. Int J Fatigue 1997;19(Supp.(1)):S109-S18.

[24] James MN, Paterson AE, Sutcliffe N. Constant and variable amplitude loading of 6261 aluminium alloy I-beams with welded cover plates-Influence of weld quality and stress relief. Int J Fatigue 1997; 19:125-33.

[25] BS 8118, The Structural use of aluminium-Part 1: Code of practice for design. British Standards Institution, 1991.

[26] Rice RC. Fatigue data analysis. In: Mechanical Testing, American Society for Metals, Mechanical Testing, 8;695-720;1990.

[27] Buch A. Verification of fatigue crack initiation life prediction results. In: TAE N. 400 TAE Report N.400, Israel Institute of Technology, Haifa, 1980. 